\title{
The Long-Term Survival of Successfully Weaned Prolonged Mechanical Ventilation Patients
}

\author{
Chienhsiu Huang (D) \\ Department of Internal Medicine, \\ Division of Chest Medicine, Dalin Tzu \\ Chi Hospital, Buddhist Tzu Chi Medical \\ Foundation, Dalin, Chiayi County, Taiwan
}

Background: There are rare articles in the literature that addressed long-term survival in successfully weaned prolonged mechanical ventilation patients. How are the long-term outcomes of these successfully weaned prolonged mechanical ventilation patients? Our objective is to explore this issue in depth in this study and serve as the basis for us to provide suggestions for patients in long-term care of the successfully weaned prolonged mechanical ventilation patients.

Methods: We investigated the clinical variables, long-term survival, cause of death, receipt or not of tracheostomy and analyzed the factors association with survival in successfully weaned prolonged mechanical ventilation patients.

Results: We can further gather long-term follow-up data on successfully weaned prolonged mechanical ventilation patients, 243 patients. The 1-, 2-, 3-, 4- and 5-year survival rates of successfully weaned PMV patients were $32.5 \%, 28.0 \%, 24.9 \%, 23.9 \%$, and $21.3 \%$, respectively. The factors between successfully weaned prolonged mechanical ventilation patients who died in the ward and those who were discharged from the hospital revealed the poorer survival of patients who died in the ward was due to a higher percentage of end-stage renal disease comorbidity, a higher percentage of $\geq 4$ comorbidities and a lower percentage of undergoing tracheostomy. The factors between successfully weaned discharged prolonged mechanical ventilation patients who survived $<1$ year and those who survived $\geq 1$ year revealed the poorer survival of patients who survived $<1$ year was due to older age, a higher percentage of $\geq 4$ comorbidities, and a lower percentage of undergoing tracheostomy. Conclusion: The receipt or not of tracheostomy is the key influential factor of long-term survival of successfully weaned prolonged mechanical ventilation patients. Tracheostomy should be attempted in suitable patients for improving long-term outcomes in successfully weaned prolonged mechanical ventilation patients.

Keywords: prolonged mechanical ventilation, respiratory care center, successfully weaned from ventilation, one-year survival rate, tracheostomy

\section{Introduction}

Many studies have explored the factors affecting the successful weaning rate in prolonged mechanical ventilation (PMV) patients, which ranges from $32.3 \%$ to $68.1 \%$. The predictors of successful weaning included the cause underlying the need for PMV, blood urea nitrogen and albumin levels, APACHE II score, and the number of comorbidities. ${ }^{1-10}$ Many studies have also explored the factors related to 1-year survival in PMV patients, which ranges widely from $24.3 \%$ to $61 \%$. $^{3,11-18}$ The factors related to 1-year survival of PMV patients include successful weaning from ventilation, age, comorbidities, APACHE II score, thrombocytopenia, and the need for vasopressors. Research has shown that being weaned from mechanical
Correspondence: Chienhsiu Huang Division of Chest Medicine, Dalin Tzu Chi Hospital, Buddhist Tzu Chi Medical Foundation, NO. 2, Min-Sheng Road, Dalin Ton, Chiayi County, Taiwan Email hgssport@yahoo.com.tw 
ventilation is a key factor in the long-term outcomes of PMV patients. There are rare articles in the literature that addressed long-term survival in successfully weaned prolonged mechanical ventilation patients.

The "Trial Plan for National Public Health Insurance Ventilator Dependent Patients Comprehensive Care System" began in Taiwan in July 2000. ${ }^{19}$ The program covers mechanical ventilator care in the following settings: intensive care unit, Respiratory Care Center (RCC) (a subacute stage for weaning training), respiratory care ward (RCW) (a chronic phase or long-term care), and home care service (a stable period during which the patient is cared for directly by family caregivers or by nursing home nurses). From these, we were able to further gather long-term follow-up data on 243 successfully weaned RCC PMV patients for six years. This present study was conducted to evaluate the factors influencing the survival of patients with successfully weaned from PMV. We believe this study would be of importance to the patients and family members as our findings will assist them in terms of clinical decision-making.

\section{Methods}

\section{Design and Setting}

Details of Hospital ${ }^{20}$

The Dalin Tzu Chi Hospital is a tertiary-level teaching hospital with 600 acute care beds and an ICU containing 59 beds. A 10-bed ventilator weaning unit (RCC) is available within Dalin Tzu Chi Hospital which is a weaning unit within an acute-care hospital, provides care for patients on PMV.

\section{Patient Details}

We conducted a retrospective study of a single institution's experience and enrolled all those who were successfully weaned from PMV and consecutively admitted to the RCC of Dalin Tzu Chi Hospital between 1 January 2012 and 31 December 2017. Patients were eligible for RCC admission if they met the Taiwan National Health Insurance requirements. Exclusion criteria was as follows: (1) If the patient does not have an outpatient visit medical record after they were discharged from the hospital, the patients are classified as lost follow-up patients. (2) If the patient has an outpatient visit medical record after they were discharged from the hospital, we cannot be sure whether the patient remains surviving until Dec 31, 2018, the patients are classified as lost follow-up patients. A PMV patient was defined as one using a mechanical ventilator for at least six hours daily for $>21$ consecutive days. ${ }^{21}$ Successful weaning was defined as the patient being independent from the mechanical ventilator for five consecutive days and nights. These patients were transferred to the ward for further care. We classified the successfully weaned PMV patients into three groups: (1) ward mortality patients who died in the ward before hospital discharge; (2) discharged PMV patients who were discharged from the hospital, but survived $<1$ year; and (3) discharged PMV patients who were discharged from the hospital and survived $\geq 1$ year, including surviving patients. The methods to assess the 1-year survival of patients are as follows: (1) we reviewed the medical records of outpatient visits of all successfully weaned discharged patients until Dec 31, 2018. (2) we reviewed whether the patient had died and issued a death certificate for the dead patient until Dec 31, 2018. We collected data on all patients successfully weaned from the ventilator, including age, gender, comorbidities, cause of acute respiratory failure leading to patients requiring PMV, receipt or not of tracheostomy, and long-term survival. We also analyzed the factors association with survival in these patients.

\section{Comorbidities $^{20}$}

The number of comorbidities was assessed. These included cardiovascular disease (such as essential hypertension, decompensated heart failure, coronary atherosclerotic disease, acute myocardial infarction), chronic lung disease (such as chronic obstructive pulmonary disease, asthma, bronchiectasis, interstitial lung disease), chronic kidney disease (CKD) (not requiring dialysis), end-stage renal disease (ESRD) (requiring dialysis before admission), neurologic disease (such as bed-ridden stroke survivors, or those with dementia or parkinsonism), chronic liver disease (such as chronic hepatitis, liver cirrhosis), metabolic disease (such as diabetes mellitus or other endocrine disorders requiring treatment), malignant diseases, and miscellaneous diseases.

\section{Ethics Approval and Consent to Participate}

Our study was a retrospective analysis of medical records. The study represented the lowest risk to the research subject and all information was made anonymous before being made available for research. The study was performed at the respiratory care center of Dalin Tzu Chi Hospital from January 2017 to December 2019. 
The study conformed to the Declaration of Helsinki 1975, revised Hong Kong 1989. The project was approved by the Buddhist Dalin Tzu Chi General Hospital Research Ethics Committee (Approved IRB No.: B10802009), which exempted the study from the requirement for informed consent.

\section{Statistical Analysis}

Continuous variables were expressed as mean \pm standard deviation or median, whereas categorical variables were expressed as frequencies and percentages. The differences in age cohorts, cause of acute respiratory failure leading to patients requiring PMV, receipt or not of tracheostomy, medical type of comorbidities, and number of comorbidities were evaluated using the Student's $t$-test for continuous variables and Pearson chi-square test and Fisher's exact test for categorical variables. Univariate analysis was used to analyze the association of each variable among the three patient groups (ward mortality patients, <1-year survival discharged PMV patients, and $\geq 1$-year survival discharged PMV patients). The factors show the P-value $<0.05$ of univariate analysis and enter the multivariate analysis to assess the impact of each variable on three patient groups. All statistical analyses were conducted using the statistical package SPSS for Windows (Version 17.0, SPSS, Inc., Chicago, IL), and a P value $<0.05$ was considered to show statistical significance.

\section{Results}

Over six years, 574 patients were admitted to the RCC. Of these, 428 patients $(74.6 \%)$ were older than 65 years, 357 $(62.2 \%)$ were men, and 217 (37.8\%) were women. Three hundred and ninety-one patients $(68.1 \%)$ were successfully weaned from the ventilator, including 242 men and 149 women. We were able to further gather long-term follow-up data on 243 successfully weaned PMV patients (146 men and 97 women), up to December 31, 2018, and to determine the factors associated with survival in these patients. There are 86 ward mortality patients, 78 discharged PMV patients with survived $<1$ year, and 79 discharged PMV patients with survived $\geq 1$ year. The 1-, 2-, 3-, 4- and 5-year survival rates of successfully weaned PMV patients were $32.5 \%, 28.0 \%, 24.9 \%, 23.9 \%$, and $21.3 \%$, respectively. The median survival time was four months (Figure 1). Table 1 shows the clinical variables and receipt or not of tracheostomy between ward mortality patients and discharged PMV patients. The mean age

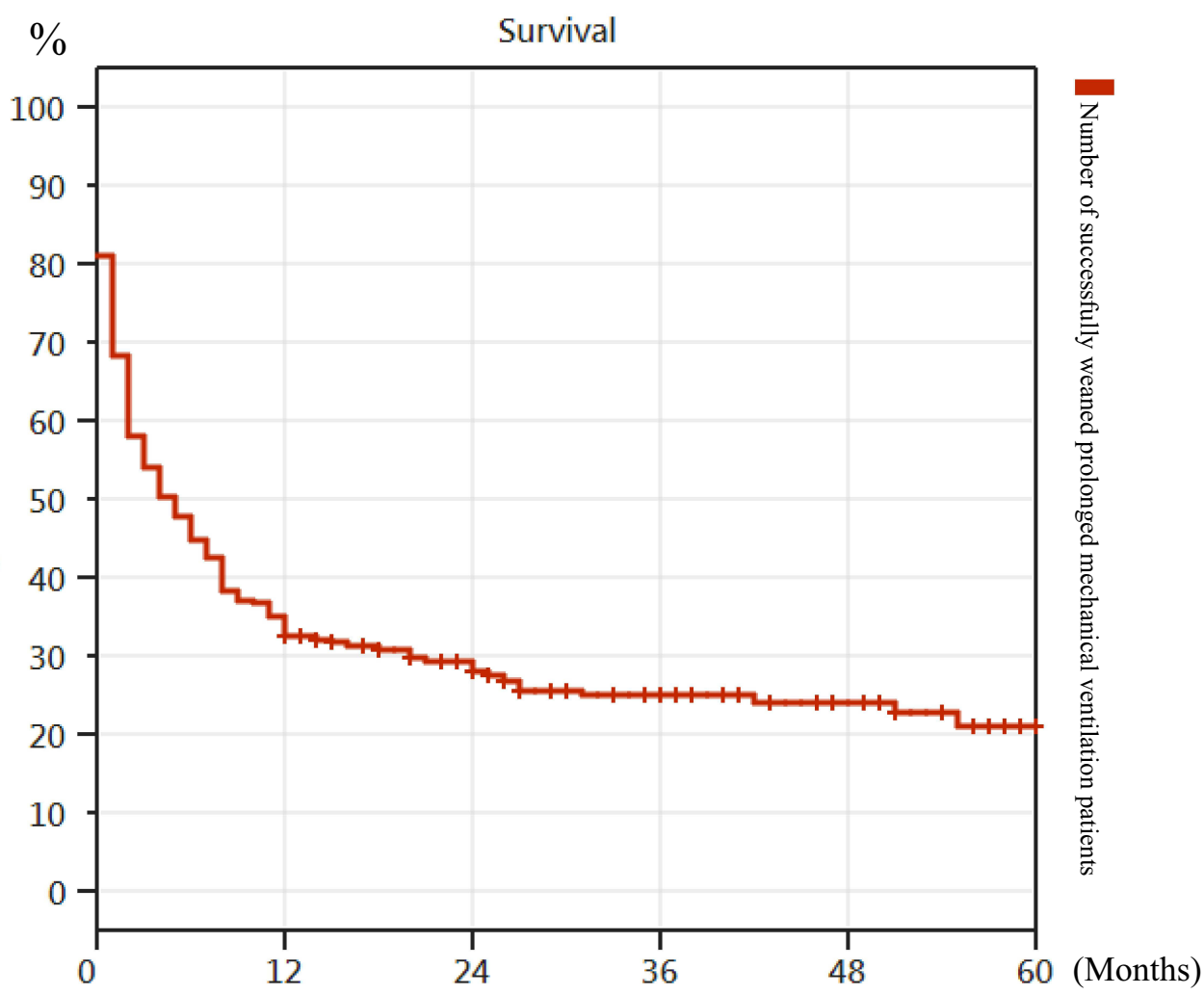

Figure I The I-, 2-, 3-, 4- and 5-year survival rates of successfully weaned prolonged mechanical ventilation patients were $32.5 \%, 28.0 \%, 24.9 \%, 23.9 \%$, and $21.3 \%$, respectively. The median survival time was four months. 
Table I Comparison of Clinical Variables and Tracheostomy Between Ward Mortality Patients and Discharged PMV Patients

\begin{tabular}{|c|c|c|c|c|}
\hline & $\begin{array}{l}\text { Ward Mortality Patients } \\
\qquad(\mathrm{No}=86)\end{array}$ & $\begin{array}{l}\text { Discharged PMV Patients } \\
(\mathbf{N o}=157)\end{array}$ & $\mathbf{P}$ & OR \\
\hline Tracheostomy, No & $4(4.65 \%)$ & $29(18.47 \%)$ & 0.005 & 4.645 \\
\hline \multicolumn{5}{|l|}{ Age Groups, No } \\
\hline Age <45 Y/O, No & $3(3.49 \%)$ & $4(2.55 \%)$ & 0.676 & 0.723 \\
\hline Age $45-54$ Y/O, No & $6(6.98 \%)$ & I4(8.92\%) & 0.600 & 1.305 \\
\hline Age 55-64 Y/O, No & $7(8.14 \%)$ & $22(\mid 4.01 \%)$ & 0.182 & 1.839 \\
\hline Age 65-74 Y/O, No & $22(25.58 \%)$ & $36(22.93 \%)$ & 0.643 & 0.866 \\
\hline Age $75-84$ Y/O, No & $34(39.53)$ & $5 \mathrm{I}(32.48 \%)$ & 0.271 & 0.736 \\
\hline Age $\geq 85$ Y/O, No & $14(16.28 \%)$ & $30(19.11 \%)$ & 0.584 & 1.215 \\
\hline \multicolumn{5}{|l|}{ Causes of respiratory failure led to PMV, No } \\
\hline Pneumonia, No & $31(36.04 \%)$ & $65(41.4 \%)$ & 0.415 & 1.254 \\
\hline Intracranial hemorrhage, No & $20(23.26 \%)$ & $31(19.75 \%)$ & 0.521 & 0.812 \\
\hline Sepsis, No & $10(11.63 \%)$ & II(7.0I\%) & 0.225 & 0.573 \\
\hline COPD, No & $2(2.33 \%)$ & $7(4.46 \%)$ & 0.408 & 1.960 \\
\hline Cardiac disease, No & $6(6.98 \%)$ & $8(5.1 \%)$ & 0.549 & 0.761 \\
\hline Malignant patients, No & $2(2.33 \%)$ & $3(1.91 \%)$ & 0.828 & 0.818 \\
\hline Post operation, No & $3(3.49 \%)$ & $12(7.64 \%)$ & 0.209 & 2.290 \\
\hline Cervical spine diseases, No & $0(0 \%)$ & $3(1.91 \%)$ & 0.554 & 0.981 \\
\hline Post-CPCR, No & $2(2.33 \%)$ & $2(1.27 \%)$ & 0.544 & 0.542 \\
\hline Cerebral infarction, No & $3(3.49 \%)$ & $3(1.91 \%)$ & 0.455 & 0.539 \\
\hline \multicolumn{5}{|l|}{ Comorbidity, No } \\
\hline Cardiovascular disease, No & $58(67.44 \%)$ & $100(63.7 \%)$ & 0.558 & 0.847 \\
\hline Chronic lung disease, No & $13(15.12 \%)$ & $36(22.93 \%)$ & 0.149 & 1.671 \\
\hline Chronic kidney disease, No & $16(18.6 \%)$ & $16(10.19 \%)$ & 0.067 & 0.496 \\
\hline End-stage renal disease (requiring dialysis), No & $12(13.95 \%)$ & $9(5.73 \%)$ & 0.034 & 0.375 \\
\hline Neurologic disease, No & $27(31.4 \%)$ & $52(33.12 \%)$ & 0.517 & 1.208 \\
\hline Metabolic disease, No & $39(45.35 \%)$ & $56(35.67 \%)$ & 0.140 & 0.668 \\
\hline Malignant diseases, No & $15(17.44 \%)$ & $16(10.19 \%)$ & 0.109 & 0.537 \\
\hline Zero comorbidities, No & $4(4.65 \%)$ & $19(12.1 \%)$ & 0.067 & 2.822 \\
\hline One comorbidity, No & $25(29.07 \%)$ & $33(21.02 \%)$ & 0.161 & 0.649 \\
\hline Two comorbidities, No s & $27(31.4 \%)$ & $53(33.76 \%)$ & 0.708 & 1.114 \\
\hline Three comorbidities, No & $14(16.28 \%)$ & $40(25.48 \%)$ & 0.102 & 1.758 \\
\hline$\geq$ Four comorbidities, No & $16(18.6 \%)$ & $12(7.64 \%)$ & 0.013 & 0.362 \\
\hline
\end{tabular}

Abbreviations: No, number; Y/O, years old; PMV, prolonged mechanical ventilation; COPD, chronic obstructive pulmonary disease; CPCR, cardiopulmonary-cerebral resuscitation.

was no significantly different between ward mortality patients and discharged PMV patients (72.4 vs 73.8 years, $\mathrm{P}=0.444)$. Table 2 shows the clinical variables and receipt or not of tracheotomy between discharged PMV patients who survived $<1$ year and those who survived $\geq 1$ year. The mean age was significantly different between discharged PMV patients who survived $<1$ year and those who survived $\geq 1$ year (78.1 vs 66.8 years, $\mathrm{P}<0.001$ ).

A multivariate analysis comparing the clinical variables and receipt or not of tracheostomy between ward mortality and discharged PMV patients showed that ESRD, receipt or not of tracheostomy, and $\geq 4$ comorbidities were significantly different (Table 3). A similar multivariate analysis between discharged PMV patients who survived $<1$ year and $\geq 1$ year showed that age $\geq 85$ years, receipt or not of tracheostomy, zero comorbidities, and $\geq 4$ comorbidities were significantly different (Table 4).

\section{Discussion}

This study aims to evaluate the factors influencing the long-term survival of patients with successfully weaned from PMV. There are three factors related to long-term survival of successfully weaned prolonged mechanical 
Table 2 Comparison of Clinical Variables and Tracheostomy Between Discharged PMV Patients Who Survived $<1$ Year and Those Who Survived $\geq 1$ Year

\begin{tabular}{|c|c|c|c|c|}
\hline & < I Year $(\mathrm{No}=78)$ & $\geq 1$ Year $(\mathrm{No}=79)$ & $\mathbf{P}$ & OR \\
\hline Tracheostomy, No & $9(11.54 \%)$ & $20(25.32 \%)$ & 0.030 & 2.599 \\
\hline \multicolumn{5}{|l|}{ Age Groups, No } \\
\hline Age $<45$ Y/O, No & $0(0 \%)$ & $4(5.06 \%)$ & 0.120 & 1.053 \\
\hline Age 45-54 Y/O, No & $2(2.56 \%)$ & $12(15.19 \%)$ & 0.014 & 6.806 \\
\hline Age 55-64 Y/O, No & $5(6.41 \%)$ & $17(2 \mid .52 \%)$ & 0.010 & 4.003 \\
\hline Age 65-74 Y/O, No & $18(23.08 \%)$ & $18(22.79 \%)$ & 0.965 & 0.984 \\
\hline Age 75-84 Y/O, No & $30(38.46 \%)$ & $2 \mathrm{I}(26.58 \%)$ & 0.114 & 0.579 \\
\hline Age $\geq 85$ Y/O, No & $23(29.49 \%)$ & $7(8.86 \%)$ & 0.002 & 0.232 \\
\hline \multicolumn{5}{|l|}{ Causes of respiratory failure } \\
\hline \multicolumn{5}{|l|}{ Led to PMV, No } \\
\hline Pneumonia, No & $38(48.72 \%)$ & $27(34.18 \%)$ & 0.066 & 0.547 \\
\hline Intracranial hemorrhage, No & $9(11.54 \%)$ & $22(27.85 \%)$ & 0.012 & 2.959 \\
\hline Sepsis, No & $6(7.69 \%)$ & $5(6.33 \%)$ & 0.738 & 0.811 \\
\hline COPD, No & $4(5.13 \%)$ & $3(3.8 \%)$ & 0.687 & 0.730 \\
\hline Cardiac disease, No & $6(7.69 \%)$ & $2(2.53 \%)$ & 0.162 & 0.312 \\
\hline Malignant patients, No & $3(3.85 \%)$ & $0(0 \%)$ & 0.120 & 0.962 \\
\hline Post operation, No & $5(6.41 \%)$ & $7(8.86 \%)$ & 0.565 & 1.419 \\
\hline C-spine diseases, No & $\mathrm{I}(\mathrm{I} .28 \%)$ & $2(2.53 \%)$ & 0.575 & 2.000 \\
\hline Post-CPCR, No & $0(0 \%)$ & $2(2.53 \%)$ & 0.497 & 1.026 \\
\hline Cerebral infarction, No & $0(0 \%)$ & $3(3.8 \%)$ & 0.245 & 1.039 \\
\hline \multicolumn{5}{|l|}{ Comorbidity, No } \\
\hline Cardiovascular disease, No & $56(71.79 \%)$ & $44(55.7 \%)$ & 0.037 & 0.494 \\
\hline Chronic lung disease, No & $20(25.64 \%)$ & $16(20.25 \%)$ & 0.432 & 0.737 \\
\hline Chronic kidney disease, No & $12(15.38 \%)$ & $4(5.06 \%)$ & 0.041 & 0.293 \\
\hline End-stage renal disease (requiring dialysis), No & $6(7.69 \%)$ & $3(3.8 \%)$ & 0.303 & 0.474 \\
\hline Neurologic disease, & $29(37.18 \%)$ & $23(29.11 \%)$ & 0.284 & 0.694 \\
\hline Metabolic disease, No & $3 \mathrm{I}(39.74 \%)$ & $25(31.65 \%)$ & 0.290 & 0.702 \\
\hline Malignant diseases, No & $10(12.82 \%)$ & $6(7.59 \%)$ & 0.284 & 0.559 \\
\hline No comorbidity, No & $3(3.85 \%)$ & $16(20.25 \%)$ & 0.005 & 6.349 \\
\hline One comorbidity, No & $15(19.23 \%)$ & $18(22.79 \%)$ & 0.585 & 1.239 \\
\hline Two comorbidities, No & $28(35.9 \%)$ & $25(31.64 \%)$ & 0.573 & 0.827 \\
\hline Three comorbidities, No & $22(28.2 \%)$ & $18(22.79 \%)$ & 0.436 & 0.751 \\
\hline 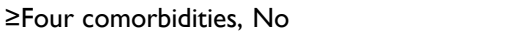 & $10(12.82 \%)$ & $2(2.53 \%)$ & 0.029 & 0.177 \\
\hline
\end{tabular}

Abbreviations: No, number; Y/O, years old; PMV, prolonged mechanical ventilation; COPD, chronic obstructive pulmonary disease; CPCR, cardiopulmonary-cerebral resuscitation.

ventilation ward mortality patients. There are four factors related to long-term survival of successfully weaned discharged PMV patients who survived $<1$ year. In western countries, PMV patients are admitted to weaning centers, and the successfully weaned PMV patients are discharged soon; thus, none of these patients die in a ward. Thus, there are no articles discussing patients with PMV ward mortality in the literature. In our RCC, which is a weaning unit in an acute care hospital, many PMV patients are successfully weaned in the RCC and then transferred to the ward, only to die before being discharged. The research focus is the long-term outcome of successfully weaned PMV patients. Besides, this research reflects the culture of Taiwan. To our knowledge, we did not find any similar studies in the international literature related to the long-term outcome of successfully weaned PMV patients. Thus far, only one study by Schönhofer et al reported that the 1-, 3-, and 5 -year post-discharge survival rates of successfully weaned PMV patients were $49.4 \%, 38.1 \%$, and $33.4 \%$, respectively. ${ }^{22}$ The topic addressed in the study by Schönhofer et al was different from that addressed in 
Table 3 The Difference in Clinical Variables and Tracheostomy Between Ward Mortality Patients and Discharged PMV Patients

\begin{tabular}{|l|l|l|l|}
\hline & Odds Ratios & 95\% Confidence & $\mathbf{P}$ \\
\hline Univariate analysis & & & \\
ESRD comorbidity & 0.375 & $0.151-0.930$ & 0.034 \\
$\geq$ Four comorbidities & 0.362 & $0.163-0.807$ & 0.013 \\
Tracheostomy & 4.645 & $1.575-13.687$ & 0.005 \\
\hline Multivariate analysis* & & & \\
ESRD comorbidity & 0.335 & $0.125-0.898$ & 0.030 \\
$\geq$ Four comorbidities & 0.353 & $0.151-0.824$ & 0.016 \\
Tracheostomy & 6.310 & $1.955-20.359$ & 0.002 \\
\hline
\end{tabular}

Note: *The factors show the $\mathrm{P}$-value $<0.05$ of univariate analysis and enter the multivariate analysis.

Abbreviations: PMV, prolonged mechanical ventilation; ESRD, end-stage renal disease.

Table 4 The Difference in Clinical Variables and Tracheostomy Between Discharged PMV patients Who Survived <I Year and Those Who Survived $\geq 1$ Year

\begin{tabular}{|l|l|l|l|}
\hline & $\begin{array}{l}\text { Odds } \\
\text { Ratios }\end{array}$ & 95\% Confidence & $\mathbf{P}$ \\
\hline Univariate analysis & & & \\
Age $\geq 85$ years & 0.232 & $0.093-0.581$ & 0.002 \\
Intracranial & 2.959 & $1.263-6.931$ & 0.012 \\
hemorrhage & & & \\
CV comorbidity & 0.494 & $0.254-0.959$ & 0.037 \\
CKD comorbidity & 0.293 & $0.090-0.954$ & 0.041 \\
Zero comorbidities & 6.349 & $1.769-22.786$ & 0.005 \\
$\geq$ Four comorbidities & 0.177 & $0.037-0.835$ & 0.029 \\
Tracheostomy & 2.599 & $1.100-6.142$ & 0.030 \\
\hline Multivariate analysis* & & & \\
Age $\geq 85$ years & 0.028 & $0.084-0.616$ & 0.004 \\
Zero comorbidity & 5.203 & $1.127-24.028$ & 0.035 \\
$\geq$ Four comorbidities & 0.099 & $0.016-0.608$ & 0.013 \\
Tracheostomy & 4.439 & $1.551-12.701$ & 0.005 \\
\hline
\end{tabular}

Note: *The factors show the P-value $<0.05$ of univariate analysis and enter the multivariate analysis.

Abbreviations: PMV, prolonged mechanical ventilation; CV, cardiovascular disease; CKD, chronic kidney disease.

our study. Therefore, we can only analyze our own research results and hope that this result can inspire a similar discussion.

\section{Factors Affecting Survival in Successfully Weaned PMV Patients Who Died in the Ward}

Patients who died in the ward before hospital discharge had the worst outcomes of successfully weaned PMV patients that was not affected by patients' age and cause of acute respiratory failure leading to patients requiring PMV. Our study identified three factors (ESRD, $\geq 4$ comorbidities and no receipt of tracheostomy) that had a strong association with ward mortality in successfully weaned PMV patients. Comparison between ward mortality patients ward and PMV discharged patients revealed that the poorer survival of the former group was due to higher percentages of cases with ESRD (13.9\%) and $\geq 4$ comorbidities (18.6\%). Besides, only 4 ward mortality patients (4.6\%) underwent tracheostomy. The most common disease of death in ward mortality patients was respiratory disease, including 44 pneumonia patients, 17 respiratory distress patients (such as COPD, sputum impaction and upper airway obstruction). We believe that ward mortality patients who have undergone tracheostomy have a favorable better survival rate.

\section{Factors Affecting Survival in Successfully Weaned Discharged PMV Patients}

The poorer survival of the successfully weaned PMV patients who survival $<1$ year were due to three factors-age $\geq 85$, multiple comorbidities and no receipt of tracheostomy. Patients who survived $<1$ year $(29.5 \%$ of whom were $\geq 85$ years) were older than those who survived for $\geq 1$ year (only $8.9 \%$ of whom were $\geq 85$ years). Patients who survived $<1$ year $(12.8 \%$ of whom were $\geq$ four comorbidities and $3.8 \%$ of whom were zero comorbidities) were more comorbidities than those who survived for $\geq 1$ year $(2.5 \%$ of whom were $\geq$ four comorbidities and $20.3 \%$ of whom were zero comorbidities). Patients who survived $<1$ year (only $11.5 \%$ of whom underwent tracheostomy) were fewer number of patient receipt tracheostomy than those who survived for $\geq 1$ year ( $25.3 \%$ of whom underwent tracheostomy). When successfully weaned PMV patients with age $<85$ years and fewer comorbidities are expected to survive for a long time, they are strongly advised to undergo tracheostomy.

\section{Tracheostomy in Successfully Weaned PMV Patients}

Tracheostomy is recommended for PMV patients. However, most patients or family members do not want this procedure done in Taiwan. Patients and their families have some objectively incorrect views about tracheostomy. The following are some of the incorrect opinions regarding tracheostomy: 1) it will prolong the patient's disease course and increase the burden on the family; 2) it will 
increase patient pain and shorten the individual's life; and 3) after a tracheostomy, the tube cannot be removed permanently, and the patient will be bed ridden for life. ${ }^{23}$ The Clinical Performance Indicators data revealed that the tracheostomy rate of PMV patients in the RCC medical center was about 39\%. Literatures displayed that PMV patients who have undergone tracheostomy have a favorable better 1-year survival rate and lower inhospital mortality. ${ }^{18,23,24}$ This study shows that PMV patients with receipt of tracheostomy is a key factor related to good progress of successfully weaned PMV patients, including ward mortality patients and discharged PMV patients. Tracheostomy should be attempted in suitable patients for improving long-term outcomes in successfully weaned PMV patients.

\section{End-of-Life Decisions in Successfully Weaned PMV Patients}

The patients in our study displayed an excellent successful weaning rate $(68.1 \%)$ but an abysmal 1-year survival rate $(24.3 \%)$, and we believe that this poor 1-year survival rate was driven by the high mortality rate in the ward. ${ }^{1}$ Being successfully weaned did not substantially help these patients. Despite being successfully weaned from mechanical ventilation, the patients experienced suffering during their time receiving critical care involving PMV. This experience is a very shocking and painful one for the patients. After successful weaning, most of the patients are in poor health or unconscious in the ward and do not recover rapidly. In our study, the families of 177 (72.8\%) patients successfully weaned from PMV had signed the do-not-resuscitate order, in including 76 ward mortality patients and 101 discharged PMV. Patients' families typically do not want their loved ones to reexperience that suffering. They likely believe that palliative therapy could be of greater benefit for these patients.

\section{Limitations of Our Study}

We did not collect patient's laboratory data, respiratory parameters, APACHE II score, Glasgow Coma Scale, or other similar relevant variables. We were, therefore, unable to determine which of these measures, if any, may be related to the long-term survival of successfully weaned PMV patients. Our conclusions on the long-term outcomes of successfully weaned PMV patients must be interpreted with care since they derive only from our retrospective single-unit study. We have no proper strategy to improve the survival rate of ward mortality patients. We expect that the addition of other clinical experiences and strategies to improve long-term survival in successfully weaned PMV patients will yield additional insights.

\section{Conclusion}

In this study, 243 PMV patients were successfully weaned from invasive ventilation, and their 1-year survival rate was $32.5 \%$. Overall, $35.4 \%$ of these patients died in the ward before being discharged, which was because of the low percentage of patients undergoing tracheostomy in this group. The receipt or not of tracheostomy is the key influential factor of long-term survival of successfully weaned PMV patients. Tracheostomy should be attempted in suitable patients for improving long-term outcomes in successfully weaned PMV patients.

\section{Data Sharing Statement}

The datasets used and/or analyzed during the current study are available from the corresponding author on reasonable request.

\section{Ethics Approval}

The project was approved by Buddhist Dalin Tzu Chi General Hospital research ethics committee (Approved IRB No.: B10802009).

\section{Funding}

There was no funding in this study.

\section{Disclosure}

The author declares no competing interests in this work.

\section{References}

1. Huang $\mathrm{CH}$. How prolonged mechanical ventilation is a negligent disease in chest medicine - a study of prolonged mechanical ventilation based on six years' experience in Taiwan. Ther Adv Respir Dis. 2019;13:1-11. doi:10.1177/1753466619878552

2. Modawal A, Candadai NP, Mandell KM, et al. Weaning success among ventilator-dependent patients in a rehabilitation facility. Arch Phys Med Rehabil. 2002;83:154-157. doi:10.1053/apmr.2002.29614

3. Pilcher DV, Bailey MJ, Treacher DF, Hamid S, Williams AJ, Davidson AC. Outcomes, cost and long-term survival of patients referred to a regional weaning centre. Thorax. 2005;60:187-192. doi:10.1136/thx.2004.026500

4. Su J, Lin CY, Chen PJ, Lin FJ, Chen SK, Kuo HT. Experience with a step-down respiratory care center at a tertiary referral medical center in Taiwan. J Crit Care. 2006;21:156-161. doi:10.1016/j.jcrc.2005.10.004 5. Yang PH, Hung LY, Yang CJ, et al. Successful weaning predictors in a respiratory care center in Taiwan. Kaohsiung $J$ Med Sci. 2008;24:85-91. doi:10.1016/S1607-551X(08)70102-5 
6. Wu YK, Kao KC, Hsu KH, Hsieh MJ, Tsai YH. Predictors of successful weaning from prolonged mechanical ventilation in Taiwan. Respir Med. 2009;103:1189-1195. doi:10.1016/j. rmed.2009.02.005

7. Frengley JD, Sansone GR, Shakya K, Kaner RJ. Prolonged mechanical ventilation in 540 seriously ill older adults: effects of increasing age on clinical outcomes and survival. J Am Geriatric Society. 2014;62:1-9. doi:10.1111/jgs.12597

8. Lin CW, Chen NH, Wu WF, Yen YS, Li LF. Indicators of successful weaning from prolonged mechanical ventilation in a subacute respiratory care ward in northern Taiwan. Thorac Med. 2015;30:9-17.

9. Shin HJ, Chang JS, Ahn S, et al. Clinical factors associated with weaning failure in patients requiring prolonged mechanical ventilation. $J$ Thorac Dis. 2017;9:143-150. doi:10.21037/ jtd.2017.01.14

10. Damuth E, Mitchel JA, Bartock J, Roberts BW, Trzeciak S. Longterm survival of critically ill patients treated with prolonged mechanical ventilation: a systematic review and meta-analysis. Lancet Respir Med. 2015;7:544-553. doi:10.1016/S2213-2600(15)00150-2

11. Stoller JK, Xu M, Mascha E, Rice R. Long-term outcomes for patients discharged from a long-term hospitalbased weaning unit. Chest. 2003;124:1892-1899. doi:10.1378/chest.124.5.1892

12. Scheinhorn DJ, Hassenpflug MS, Votto JJ, et al. Post-ICU mechanical ventilation at 23 long-term care hospitals: a multicenter outcomes study. Chest. 2007;131:85-93. doi:10.1378/chest.06-1081

13. Bigatello LM, Stelfox HT, Berra L, Schmidt U, Gettings EM. Outcome of patients undergoing prolonged mechanical ventilation after critical illness. Crit Care Med. 2007;35:2491-2497. doi:10.1097/01.CCM.0000287589.16724.B2

14. Cox CE, Martinu T, Sathy SJ, et al. Expectations and outcomes of prolonged mechanical ventilation. Crit Care Med. 2009;37:2888-2894. doi:10.1097/CCM.0b013e3181ab86ed

15. Carson SS, Kahn JM, Hough CL, et al. A multicenter mortality prediction model for patients receiving prolonged mechanical ventilation. Crit Care Med. 2012;40:1171-1176. doi:10.1097/ CCM.0b013e3182387d43

16. Rose L, Fraser IM. Patient characteristics and outcomes of a provincial prolonged-ventilation weaning centre: a retrospective cohort study. Can Respir J. 2012;19:216-220. doi:10.1155/2012/ 358265
17. Lin MS, Yan YH, Wang JD, et al. Improved survival for an integrated system of reduced intensive respiratory care for patients requiring prolonged mechanical ventilation. Respir Care. 2013;58:517-524.

18. Hung CT, Lin JW, Ruan SY, Chen CY, Yu CJ. Preadmission tracheostomy is associated with better outcomes in patients with prolonged mechanical ventilation in the postintensive care respiratory care setting. J Formosan Med Assoc. 2017;116:169-176. doi:10.1016/j.jfma.2016.05.005

19. Bureau of National Health Insurance. Prospective payment system of ventilator dependents managed care demonstration. Available from: https:/www.nhi.gov.tw/Resource/webdata/13988_1_1050002331-1. pdf. Accessed July 16, 2021.

20. Huang C, Chen JC. The long-term survival of intracranial hemorrhage patients successfully weaned from prolonged mechanical ventilation. Int J Gen Med. 2021;14:1197-1203. doi:10.2147/IJGM. S304228

21. MacIntyre NR, Epstein SK, Carson S, Scheinhorn D, Christopher K, Muldoon S. Management of patients requiring prolonged mechanical ventilation: report of a NAMDRC consensus conference. Chest. 2005;128:3937-3954. doi:10.1378/chest.128.6.3937

22. Schönhofer B, Euteneuer S, Nava S, Suchi S, Köhler D. Survival of mechanically ventilated patients admitted to a specialised weaning centre. Intensive Care Med. 2002;28:908-916. doi:10.1007/s00134002-1287-5

23. Huang $\mathrm{CH}$, Chen $\mathrm{IH}$. The clinical application of the tracheostomy decision-making program in respiratory care center prolonged mechanical ventilation patients in Taiwan. Int $J$ Gen Med. 2020;13:1487-1494. doi:10.2147/IJGM.S28579

24. Wu YK, Tsai YH, Lan CC, et al. Prolonged mechanical ventilation in a respiratory-care setting: comparison of outcome between tracheostomized and translaryngeal intubated patients. Crit Care. 2010;14: R26. doi: $10.1186 / \mathrm{cc} 8890$
International Journal of General Medicine

\section{Publish your work in this journal}

The International Journal of General Medicine is an international, peer-reviewed open-access journal that focuses on general and internal medicine, pathogenesis, epidemiology, diagnosis, monitoring and treatment protocols. The journal is characterized by the rapid reporting of reviews, original research and clinical studies

\section{Dovepress}

across all disease areas. The manuscript management system is completely online and includes a very quick and fair peer-review system, which is all easy to use. Visit http://www.dovepress.com/ testimonials.php to read real quotes from published authors. 